\title{
MEMAKNAI ULANG KONSEP PENDIDIKAN ISLAM (TELAAH KRITIS EPISTEMOLOGI HASAN LANGGULUNG DALAM PEMBELAJARAN DI MASA PANDEMI COVID-19)
}

\author{
Ima Frafika Sari ${ }^{1}$, Ucup Supriatna ${ }^{2}$, Afni Ma'rufah ${ }^{1}$ \\ ${ }^{1}$ Institut Agama Islam Negeri (IAIN) Ponorogo \\ ${ }^{2}$ STAI Al-Haudl Kalimantan Barat \\ *Corresponding email: ifrafika@gmail.com
}

Naskah diterima: 3 Juli 2021| Disetujui: 1 Agustus2021 | Diterbitkan: 3 Agustus 2021

\begin{abstract}
As a library research, the primary research data are in the form of six writings by Hasan Langgulung. The researcher also presented research data related to learning that had occurred during the covid-19 pandemic season. The data collection technique is done by documentation. Then the data analysis was done descriptively-analytically. Researchers generalized and critically analyzed the concept of Hasan Langgulung Islamic education from various primary and secondary literatures and then discussed the concept on the actualization of Islamic education during the covid19 pandemic season. The results of the study show that online learning that has occurred during the pandemic so far is still disoriented to the epistemology of Islamic education. Hasan Langgulung offers an epistemological paradigm of Islamic education, namely 1) teachers should formulate online learning aims and goals that are realistic and can be measured through indicators with specified timelines. Aims and learning goals are oriented to three aspects of cognitive, affective, and psychomotor; 2) choosing learning strategies to be more precise with guidance, counseling, and providing incidental student assistance; 3) the learning evaluation system must be realistic and measurable, all of which include cognitive, affective, and psychomotor aspects.
\end{abstract}

Keywords: Epistemology, Islamic Education, Hasan Langgulung, Covid-19 Pandemic

\begin{abstract}
Abstrak: Sebagai penelitian kepustakaan (library research), data primer penelitian berupa enam karya tulis Hasan Langgulung. Peneliti juga memaparkan data penelitian terkait pembelajaran yang telah terjadi selama musim pandemi covid-19. Teknik pengumpulan data dilakukan dengan dokumentasi. Kemudian analisis data dilakukan secara deskriptif-analitik. Peneliti melakukan generalisasi dan analisis kritis atas konsep pendidikan Islam Hasan Langgulung dari berbagai literatur primer dan sekunder kemudian mendialogkan konsep tersebut pada aktualisasi pendidikan Islam selama musim pandemi covid-19. Hasil penelitian menunjukkan bahwa pembelajaran daring yang telah terjadi di masa pandemi selama ini masih disorientasi dengan epistemologi pendidikan Islam. Hasan Langgulung menawarkan paradigma epistemologi pendidikan Islam, yaitu 1) hendaknya guru merumuskan aims dan goals pembelajaran daring yang realistis dan dapat diukur melalaui indikator dengan teamlines yang ditentukan. Aims dan goals pembelajaran yang berorientasi pada tiga aspek baik kognitif, afektif, dan psikomotorik; 2) pemiliah strategi pembelajaran untuk lebih tepatnya dilakukan dengan bimbingan, konseling, dan melakukan pendampingan siswa secara insindental; 3) sistem evaluasi pembelajaran harus realistis dan terukur yang keseluruhannya mencakup aspek kognitif, afektif, dan psikomotorik.
\end{abstract}

Kata kunci: Epistemologi, Pendidikan Islam, Hasan Langgulung, Pandemi Covod-19 


\section{PENDAHULUAN}

Berlangsungnya wabah covid-19 mulai akhir tahun 2019 hingga saat ini telah mengubah segala tatanan sosial masyarakat dari berbagai bidang termasuk pendidikan Islam. Pendidikan Islam menjadi sering disebut publik karena perannya yang mulai tidak berjalan maksimal sebagaimana roadmap yang dicanangkan oleh Kementerian Pendidikan dan RI dan Kementerian Agama RI. Siswa belajar di rumah melalui platform digital, metode pembelajaran yang kurang maksimal, perilaku siswa, tidak siapnya wali murid dalam mendampingi belajar, maraknya konferensi digital, sistem evaluasi pembelajaran yang kurang mengena, hingga sikap anti sosial. Semuanya sebagai dampak dari covid19 di Indonesia, sehingga banyak ilmuwan, peneliti, dan praktisi pendidikan mencari resolusi terbaik agar dinamika pendidikan dapat berjalan seperti semula.

Dampak pendidikan sebagaimana dimaksud tentu perlu dikaji ulang terutama dalam ranah epistemologi. Epistemologi pendidikan Islam menjadi basis pengembangan perilaku pendidikan Islam dan kompleksitasnya. Epistemologi menjawab dinamika pendidikan Islam meskipun bersifat sontak, karena epistemologi didapat dari berbagai sumber pengetahuan akal, pancaindra, ilham, dan budi manusia jauh melihat objek material ke depan. Hal inilah yang banyak dilupakan oleh peneliti dan praktisi pendidikan Islam. Mereka berusaha mengentaskan permasalahan pendidikan Islam dalam pusaran covid-19 melalui resolusi pragmatis, instan, dan dapat diimplementasikan secara sontak tanpa melihat asas epistemologi yang digunakan.

Terkait strategi pembelajaran, penelitian (Giyarsi, 2020) menawarkan empat strategi alternatif dalam pendidikan Islam di masa pandemi covid-19 yaitu;1) discovery learning; 2) contextual teaching learning; 3) problem based learning; dan 4) student active learning. Dengan keempat strategi tersebut, guru dapat melaksanakan keberlangsungan pendidikan dengan baik. Dalam bidang kurikulum, penelitian (Wilatikta, 2020) menyebut bahwa manajemen kurikulum pendidikan Islam harus berorientasi ke ranah kognitif siswa sebagai bentuk reaktualisasi pendidikan secara emergency. Selanjutnya peran orang tua yang diulas dalam penelitian (Ahsani, 2020) menjelaskan peran orang tua dalam mendampingi anak belajar. Menurutnya, orang tua harus memahami gaya belajar anak, sehingga orang tua dapat menyiapkan lingkungan belajar yang nyaman dan menyenangkan meskipun menggunakan metode belajar yang tradisional.

Ketiga penelitian di atas merupakan resolusi pragmatis atas dinamisasi pendidikan Islam di era pandemi covid-19. Penelitian pertama dengan menawarkan strategi pembelajaran yang selaras dengan konteks keadaan. Sementara penelitian kedua mengulas manajemen kurikulum pendidikan Islam yang dinilai tepat sasaran, sedangkan penelitian ketiga menunjukkan peran orang tua dalam mendampingi proses belajar anaknya. Ketiga penelitian di atas belum menunjukkan asas epistemologi 
pendidikan Islam secara paradigmatik, sehingga resolusi instan kurang menjawab kompleksitas pendidikan Islam secara teosentris dan antroposentris. Pernyataan demikian yang membuat peneliti menelaah lebih jauh epistemologi pendidikan Islam sebagai hasil dari ontologi yang dirumuskan. Peneliti meminjam istilah epistemologi pendidikan Islam Hasan Langgulung sebagai resolusi membaca pendidikan Islam di masa pandemi covid-19.

Epistemologi pendidikan Islam Hasan Langgulung dipilih karena berbagai alas an. Pertama, Hasan Langgulung adalah pemikir pendidikan Islam kontemporer yang berasal dari Indonesia. Kedua, Secara sosial dan budaya, pemikiran Hasan Langgung selaras dengan wajah pendidikan Islam di Indonesia. Ketiga, memiliki gagasan teosentris dan antroposentris yang dapat diaktualisasikan dalam pendidikan Islam secara kompleks.

\section{METODE}

Laporan penelitian ini adalah kualitatif dengan menggunakan pendekatan kepustakaan (library research). Sebuah penelitian yang mengulas konsep dari berbagi sumber literatur sehingga ditemui gagasan yang spesifik (Zed, 2014). Data primer penelitian berupa enam karya tulis buku Hasan Langgulung, yaitu 1) Beberapa Pemikiran Tentang Pendidikan Islam (Penerbit Maarif, 1980); 2) Dayacipta dalam Kurikulum Pendidikan Guru (Penerbit Universiti Kebangsaan Malaysia, 1984), 3) Pendidikan dan Peradaban Islam: Suatu Analisa Sosio-Psikologi (Pustaka Al-Husna, Jakarta, 1985); 4) Manusia dan Pendidikan: Suatu Analisa Psikologi, Filsafat dan Pendidikan. Pustaka al-Husna, 1986); 5). Pendidikan Islam Menghadapi Abad ke-21 (Pustaka Al Husna, 1988); 6) Pendidikan Islam dalam Abad ke-21 (Pustaka Al Husna Baru, 2003). Data sekunder penelitian berupa literatur-literatur penelitian yang mengulas konsep pendidikan Hasan Langgulung sebaimana dalam daftar pustaka serta penelitian pembelajaran daring di masa pandemi Covid-19. Teknik pengumpulan data dilakukan dengan dokumentasi. Pemikiran-pemikiran Hasan Langgulung didokumentasikan secara paradigmatik-dialektik dan disistemasikan mulai dari terminologi pendidikan Islam; tujuan pendidikan Islam, materi dan kurikulum, strategi, dan sistem evaluasi pendidikan Islam. Sebagai penelitian kepustakaan, analisis data dilakukan secara deskriptif-analitis. Sebuah analisis data yang menggeneralisasi konsep-konsep dalam kepustakaan secara kritis (Martin, 2017). Peneliti melakukan generalisasi dan analisis kritis atas epistemologi pendidikan Islam Hasan Langgulung dari berbagai literatur primer dan sekunder kemudian mendialogkannya dengan aktualisasi pendidikan Islam yang terjadi selama musim pandemi covid-19. Hasil analisis data dalam hal ini berupa paradigma pemikiran pendidikan Islam Hasan Langgulung yang kemudian disimpulkaan dan menjadi hasil penelitian. 


\section{HASIL DAN PEMBAHASAN}

\section{Hasan Langgulung dan Pendidikan Islam}

\section{Sketsa Biografi}

Sebagai seorang pemikir pendidikan Islam, gagasan Hasan Langgulung dibilang masyhur di kalangan akademisi pendidikan Islam khususnya di Indonesia. Sumbangan pemikiran pendidikan Islam di Indonesia telah ditorehkan pada dua tiga dekade silam. Hasan Langgulung lahir di Rappang Sulawes Selatan, pada tanggal 16 Oktober 1934 dan meninggal di Kuala Lumpur Malaysia, 02 Agustus 2008. Beliau mengenyam pendidikan bidang Islamic Studies di Cairo University tahun 1963, bidang psikologi dan Mental Hyegine di Eins Shams University Kairo (H Langgulung, 1988). Selanjutnya ia menekuni bidang Sastra Arab modern dan berhasil meraih Diploma di Institute of Higher Arab Studies, Arab Leage pada tahun 1964. Studi strata tiga atau Ph.D diselesaikan di University Georgia Amerika Serikat tahun 1971 (Wikipedia, 2019). Sosoknya pernah menjadi pengajar di University Kebangsaan Malaysia. Ia menjadi Profesor senior hingga beberapa tahun di sana. Meski lahir di Indonesia, kiprah keilmuan dan karier Hasan Langgulung banyak dihabiskan di luar negeri. Mendapatkan gelar Royal Profesor oleh masyarakat akademik dunia di Kuala Lumpur pada tahun 2002 (Riza, 2017).

Dalam karier keilmuan, Hasan Langgulung menggeluti bidang Psikologi, Filsafat, dan Pendidikan Islam. Beliau dikenal sebagai ilmuwan yang produktif. Beberapa tulisan baik berupa buku dan artikel telah dimuat di jurnal internasional. Hingga menjelang wafatnya, ia telah merampungkan 19 karya buku di bidang Psikologi dan Pendidikan Islam (Wikipedia, 2019). Karya-karya yang demikian mempengaruhi perkembangan studi psikologi dan pendidikan Islam khususnya di Indonesia. Hingga saat ini pemikiran pendidikan Hasan Langgulung banyak diadopsi oleh ilmuwan pendidikan Islam. Pemikiran pendidikan Islam yang dituangkannya dapat mengambah sistem pendidikan Islam yang tidak hanya sisi paradigmatis, melainkan pragmatis semisal sistem manajemen lembaga pendidikan (Mustajib, 2016). Hasan juga memberikan sumbangsih pemikiran dalam bidang psikologi yang kemudian ia relevansikan dengan psikologi pendidikan Islam (H Langgulung, 1985). Menurutnya teori-teori psikologi adalah embiro dari lahirnya teori-teori pendidikan. Ia tidak dapat memisahkan antara psikologi dan pendidikan sebagai kesatuan ilmu non-dikotomik.

\section{Epistemologi Pendidikan Islam}

Berbicara mengenai epistemologi, berarti membahas mengenai asas, proses, prosedur, metode, dan konten. Epistemologi merupakan salah satu cabang filsafat yang mendekonstruksi dasar-dasar dan batasan pengetahuan (Velasquez, 1991). Epistemologi memberi afirmasi pada ranah pendidikan Islam hingga disebut epistemologi pendidikan Islam. Terminologi yang dimaksud adalah cabang ilmu 
pengetahuan yang mengkaji dasar-dasar dan batasan pendidikan Islam (A.D. Marimba, 2014). Pendidikan Islam dibentuk dari epistemologi dan menjadi paradigma untuk membaca perannya. Pembentukan ini berlaku semenjak periode klasik hingga kontemporer (Hanafi, 2014).

Epistemologi pendidikan Islam Hasan Langgulung mencakup terminologi pendidikan Islam, tujuan pendidikan Islam, kurikulum yang di dalamnya membahas strategi dan metode, serta sistem evaluasi pendidikan (Riza, 2017). Peneliti memberi batasan pada sub tema tersebut agar pembahasan tidak terlalu melebar. Hasan Langgulung memberikan afirmasi bahwa pendidikan Islam dapat dilihat dari dua sisi, yaitu sisi teoritis dan pragmatis. Terminologi secara teoritis adalah tindakan yang dilakukan oleh individu maupun kelompok masyarakat dalam bingkai sosial, budaya, dan peradaban guna memelihara keberlangsungan hidup (Hasan Langgulung, 2003). Hasan menitik beratkan pada teks Al-Qur'an dan Hadis sebagai asas dan sumber pendidikan Islam dan pengembangan ilmu pengetahuan. Tidak berhenti di situ, ia juga menyepakati adanya kiyas dan ijmak ulama sebagai sumber hukum setelah Al-Qur'an dan Hadis (H Langgulung, 1980). Pendidikan Islam ialah proses pengembangan potensi fitrah ilāhiyyah manusia yang telah dianugerahkan kepadanya. Pendidikan Islam ialah proses melahirkan khālifah atau pemimpin di bumi sebagai bentuk isti'mār al-arḍ untuk menjalankan tugasnya dengan misi ilahi (H Langgulung, 1988).

Tujuan pendidikan Islam menurutnya adalah membentuk manusia yang saleh dengan menjalankan hak-hak Allah SWT (al-qāim biḥuqūqillāh) dan hak-hak untuk manusia (wa ḥuqūq al'ibād) (H Langgulung, 1986). Manusia yang saleh harus senantiasa memiliki karakter akhlak mulia, budi pekerti luhur, kesucian, kasih sayang, mengendalikan diri, dan bertanggung jawab. Ia harus memiliki keseimbangan dalam dirinya sehingga dapat mengontrol perilaku diri. Setelah ia selesai dengan karakter dirinya, maka ia berkewajiban untuk menanamkan sifat-sifat saleh kepada masyarakat melalui proses pendidikan. Hal ini sebagai bentuk aktualisasi ibadah manusia kepada Tuhan. Melalui pendidikan Islam, diri, dan masyarakat dapat lebih jauh mengenal Tuhannya (H Langgulung, 1980).

Penataan materi kurikulum pendidikan Islam menurut (H Langgulung, 1984) diklasifikasikan menjadi tiga baguian, yaitu 1) ilmu yang diwahyukan, 2) ilmu-ilmu humaniora, 3) ilmu alam atau sains. Ketiga ilmu tersebut harus memiliki integrasi non-dikotomi dalam menjawab permasalahan kontemporer. Ia tidak setuju dengan adanya sekulerisasi pengetahuan, yang menitikberatkan pengetahuan hanya bersifat rasional dan mengedepankan sumber akal. Epistemologi pengetahuan tidak hanya bertumpu pada manifestasi yang empiris-rasional-objektif, tetapi juga harus metaempirik-rasional-subjektif. Jika membahas perihal yang sifatnya kasat mata (tajrībī), maka metodologi pengetahuan yang digunakan ialah empiris-rasional-objektif. Namun jika mengulas 
perihal yang bersifat transendental, maka metodologi pengetahuan yang digunakan adalah metaempirik-rasional-subjektif yang berlandas pada iman dan tauhid (H Langgulung, 1986). Menurutnya, kurikulum harus senantias selaras dengan tujuan pendidikan Islam, baik tujuan yang bersifat sementara maupun jangka panjang. Sedangkan konten materi kurikulum dapat bersifat internal, yaitu materi pendidikan yang bersumber dari agama yang bersifat transendental dan normatif, serta materi yang bersifat eksternal, yaitu materi pendidikan yang bersumber dari barat. Perihal yang dimaksud di sini adalah ilmu-ilmu humaniora dan sain yang bersifat rasional. Kedua konten materi demikian dapat dipelajari secara integral agar saling menguatkan (H Langgulung, 1984).

Hasan juga menjelaskan strategi-strategi dalam mengelola pendidikan Islam. Menurutnya, strategi mikro yang tepat untuk diimplementasikan dalam pendidikan Islam adalah tazkiyah atau "penyucian" (Munawwir et al., 2002). Manusia sebagai makhluk yang dianugerahi akal dan nafsu semestinya dapat mengendalikan diri dari segala hal yang dapat mengotori jiwa, misalnya perbuatan dosa secara vertikal dan horizontal. Implementasi tazkiyah menurut (Hasan Langgulung, 2003) dilalui melalui tiga tahap, yaitu: 1) tazkiyah al-nafs atau disebut "konseling"; 2) tazkiyah al-aql atau penjernihan akal, yang dalam hal ini ialah pejernihan akidah dan penjernihan pemikiran; 3) tazkiyah al-jism atau "penjernihan badan", yang dapat diaktualisasikan dengan menyusun kebutuhan tubuh agar tetap sehat serta mengemat tenaga agar dapat mengoptimalkan perilaku-perilaku positif. Proses tazkiyah dapat dilakukan dengan beberapa metode seperti salat, puasa, dan menjalin hubungan baik kepada seksama. Dalam pendidikan modern, strategi dan metode pendidikan dapat direktualisasikan dengan metode pembelajaran yang humanis dan integratif, terlepas dari asas penggunaan strategi dan metode pendidikan tersebut.

Makna evaluasi pendidikan Islam, (H Langgulung, 1985) menyebut sebagai proses asesmen yang seyogyanya tidak bersifat tertulis, melainkan juga harus mencakup pada sikap (attitude). Evaluasi yang bersifat tertulis hanya mampu mengukur keberhasilan siswa dalam aspek kognitif, sedangkan asesmen yang bersifat afektif dapat mengukur keberhasilan siswa atas perkembanga sikap. Untuk memahami arah yang dimaksud, maka esensi evaluasi pendidikan Islam harus berpatri dalam dua misi, yaitu melahirkan pribadi muslim yang saleh (representatif), dan terbentuknya masyarakat yang turut saleh.

\section{Dialektika Paradigmatik Pendidikan Islam Di Masa Pandemi Covid-19}

Peneliti menyoroti hilangnya kerangka berpikir secara epistemologis atas berlangsungnya metode pendidikan Islam yang terjadi selama pandemi covid-19. Tiga penelitian yang dipaparkan dalam latar belakang masalah merupakan bagian kecil terkait metodologi pendidikan Islam yang 
menafikkan kerangka berpikir secara epistemologis. Sebagai dampaknya, telah terjadi disorientasi tujuan pendidikan Islam. Tujuan pendidikan Islam akan mempengaruhi konstruksi kurikulum, materi, strategi, metode, dan evaluasi pendidikan Islam. Peneliti mengajak para akademisi yang bergerak dalam disiplin ilmu pendidikan Islam untuk memahami ulang (flashback) atas epistemologi pendidikan Islam Hasan Langgulung. Tawaran epistemologi Hasan Langgulung untuk menjawab metodologi pendidikan Islam di masa pandemi covid-19.

Penelitian (Wilatikta, 2020) menyebut manajemen kurikulum pendidikan Islam harus berorientasi ke ranah kognitif siswa sebagai bentuk reaktualisasi pendidikan secara emergency. Ini merupakan pendapat yang kurang tepat jika berasas tujuan pendidikan Islam secara normatif. Pelaksanaan pembelajaran daring di masa pandemi covid-19 telah mengubah orientasi kurikulum yang dicanangkan sebelumnya. Taksonomi Bloom sebagaimana dikutip oleh (Pantiwati et al., 2016) menyebut kompleksitas kemampuan siswa dalam belajar. Menurutnya Bloom, tujuan pembelaran adalah keseimbangan kemampuan siswa secara kognitif, afektif, dan psikomotorik. Hal ini sama dengan pendapat (H Langgulung, 1980), bahwa tujuan pendidikan Islam ialah membentuk kepribadian siswa yang memiliki kepribadian baik, disamping kecerdasan kognitif dan kecerdasan psikomotorik. Pembelajaran di masa pandemi sering dilakukan secara daring melalui platform digital. Guru lebih banyak memberikan tugas dari pada menjelaskan, sehingga siswa menjadi lelah dan bosan belajar. Ditambah badanya tugas yang diberikan untuk pertemuan berikutnya. Siswa bukan robot yang selalu diberikan tugas. Siswa dapat dikatakan baik jika mampu menyerap materi maksimal 50\% dari indikator pembelajaran, mengingat siswa harus menyiapkan platform digital sebelum pelaksanaan pembelajaran. Akan sedikit terhambat bagi mereka yang gagap teknologi. Kasus demikian hanya berorientasi pada aspek kognitif siswa dan belum mengarah pada aspek afektif dan psikomotorik.

Sudah seharusnya guru merumuskan aims dan goals pembelajaran daring yang realistis dan dapat diukur melalaui indikator dengan teamlines yang ditentukan. Aims dan goals pembelajaran yang berorientasi pada tiga aspek baik kognitif, afektif, dan psikomotorik. Tidak melulu berorientasi aspek kognitif meskipun dalam keadaan emergency. Indikator secara kognitif misalnya, siswa mampu memahami minimal 50\% materi pembelajaran karena situasi pembelajaran daring. Indikator secara psikomotorik ialah siswa mampu mengoperasikan platform digital pembelajaran dengan baik. Mungkin dapat dikatakan aneh karena jauh dari aims pembelajaran dan tidak masuk dalam draft indikator pembelajaran. Namun siswa dapat belajar melalui platform digital sebelum pembelajaran dimulai sebagai bentuk daya latih skill teknologi. Hal ini sangat bermanfaat bagi siswa karena saat ini sudah masuk zaman teknologi. Indikator aspek afektif dapat dirumuskan dengan siswa mampu mengimplementasikan materi ajar ke dalam aspek kehidupan sehari-hari. Ketiga indikator (kognitif, 
afektif, dan psikomotorik) harus dapat diukur. Integrasi tiga indikator tersebut telah selaras sesuai dengan paradigma tujuan pendidikan Islam sebagaimana dijelaskan Hasan Langgulung.

Permasalahan strategi pendidikan Islam juga menjadi kajian yang penting dalam pelaksanaan pembelajaran. Pemilihan strategi dan metode pembelajaran di masa pandemi covid-19 selama ini cukup menyulitkan guru dan siswa. Contoh yang nyata adalah penelitian (Giyarsi, 2020) sebagaimana diungkap bahwa ia menawarkan empat strategi pembelajaran selama pandemi, yaitu; 1) discovery learning; 2) contextual teaching learning; 3) problem based learning; dan 4) student active learning. Jika diamati pada keempat strategi di atas sangat tepat dilakukan untuk mahasiswa di Perguruan Tinggi, namun tidak tepat untuk sasaran siswa sekolah menengah. Secara kognitif, keempat strategi belajar di atas membutuhkan penalaran dan logika berpikir kritis. Dalam aspek psikomotorik, siswa harus menemukan permasalahan terkait tema pembelajaran dan merepresentasikan hasil pembelajaran dengan baik. Ditinjau dari aspek afektif, keempat strategi pembelajaran di atas tidak selaras dengan kerangka berpikir tujuan pendidikan Islam jika dilakukan saat daring, hal itu karena menafikan indikator afektif.

Pemilihan stategi pendidikan Islam perspektif (Hasan Langgulung, 2003) dapat diaktualisasikan melalui konsep tazkiyah berupa bimbingan dan konseling. Guru dapat melaksanakan bimbingan terkait materi pembelajaran, kendala siswa saat mengikuti pembelajaran, serta perilaku siswa. Guru lebih banyak menjelaskan materi dari pada memberi tugas kepada siswa. Menjelaskan materi termasuk melakukan bimbingan secara kognitif kepada siswa, sedangkan memberikan tugas tanpa diajar terlebih dahulu akan membuahkan disorientasi psikomotorik siswa. Selain melakukan bimbingan, guru dapat memberikan pendampingan dan konseling siswa melalui kegiatan-kegiatan belajar yang mengarah pada aspek afektif, seperti kegiatan ibadah dan berolahraga secara insindental. Sekiranya guru tetap untuk menjalin komunikasi dengan wali siswa guna melakukan pendampingan belajar. Konsep ini dapat dirumuskan melalui indikator pembelajaran, sehingga pemilihan strategi pembelajaran dirasa tepat sasaran dan merasuk dalam jiwa, akal, dan badan siswa.

Sistem evaluasi pendidikan Islam yang diaktualisasikan melalui asesmen pembelajaran secara daring tidak melulu menguji secara kognitif. Hal ini banyak dilakukan oleh guru saat menghadapi Ujian Tengah Sekolah dan Ujian Akhir Sekolah. Guru lebih banyak mengevaluasi dan mengukur aspek kognitif siswa melalui ujian tertulis. (H Langgulung, 1985) memberikan komentar atas evaluasi pendidikan Islam yang seharusnya dilakukan oleh guru. Evaluasi harus mengarah kepada tiga kemampuan siswa baik secara kognitif, afektif, dan psikomotorik. Guru tidak melulu memberikan ujian tertulis meski dalam pembelajaran daring. Guru dapat melakukan asesmen afektif melalui partofolio siswa, sehingga keberhasilan attitude siswa dapat diketahui. Asesmen dinilai penting 
karena tidak menafikan aspek attitude. Attitude merupakan salah satu indikator tercapainya tujuan pendidikan Islam. Jika guru hanya melakukan asesmen kognitif melalui ujian tertulis, maka siswa akan kering pengalaman secara afektif dan psikomotorik.

Terumusnya tujuan pendidikan Islam yang realistis, pemilihan strategi, dan evaluasi yang terukur merupakan paradigma epistemologis yang komperhensif menurut (H Langgulung, 1984). Hal ini menunjukkan betapa pendidikan Islam dapat dilakukan melalui berbagai prosedur. Tugas berat seorang guru adalah mengaktualisasikan konsep pendidikan Islam melalui perumusan tujuan pembelajaran, penyusunan materi, pemilihan strategi, metode pembelajaran, serta melaksanakan evaluasi pembelajaran secara paripurna. Prosedur-prosedur demikian tentu tidak lepas dari tujuan akhir (goals) pendidikan Islam yaitu membentuk manusia yang saleh, cerdas secara kognitif, terampil secara psikomotorik, dan memiliki emosi yang baik.

\section{KESIMPULAN}

Konsep pendidikan Islam yang diaktualisasikan dalam sistem pembelajaran daring selama masa pandemi covid-19 belum sepenuhnya sesuai dengan epistemologi pendidikan Islam, terutama epistemologi Hasan Langgulung. Peneliti telah menemukan tiga penelitian terkait implementasi pembelajaran daring yang belum sesuai dengan epistemologi pendidikan Islam. Dalam ketiga penelitian tersebut didapati disorientasi tujuan pembelajaran, pemilihan strategi pembelajaran yang kurang tepat, dan sistem pelaksanaan evaluasi pembelajaran yang kurang mengukur keberhasilan siswa.

Epistemologi pendidikan Islam Hasan Langgulung dalam penerapan pembelajaran daring di masa pandemi covid-19 dapat dilakukan sebagai berikut; 1) hendaknya guru merumuskan aims dan goals pembelajaran daring yang realistis dan dapat diukur melalaui indikator dengan teamlines yang ditentukan. Aims dan goals pembelajaran yang berorientasi pada tiga aspek baik kognitif, afektif, dan psikomotorik; 2) pemilihan strategi pembelajaran dilakukan dengan cara melakukan bimbingan dan konseling. Membimbing materi belajar siswa dan berkomunikasi dengan wali siswa untuk melakukan pendampingan belajar. Melakukan pendampingan secara insindental pada hal-hal yang bersifat afektif dan psikomotorik seperti ritual ibadah dan olahraga siswa; 3) sistem evaluasi pembelajaran harus realistis dan terukur yang keseluruhannya mencakup aspek kognitif, afektif, dan psikomotorik. 


\section{DAFTAR PUSTAKA}

A.D. Marimba. (2014). Pengantar Filsafat Pendidikan Islam. Remaja Rosdakarya.

Ahsani, E. L. F. (2020). Strategi Orang Tua dalam Mengajar dan Mendidik Anak dalam Pembelajaran At The Home Masa Pandemi Covid-19. Al Athfal: Jurnal Kajian Perkembangan Anak Dan Manajemen Pendidikan Usia Dini, 3(1), 37-46.

Giyarsi, G. (2020). Strategi Alternatif Dalam Pembelajaran Daring Pendidikan Agama Islam Pada Masa Pandemi Covid 19. GHAITSA: Islamic Education Journal, 1(3), 224-244.

Hanafi, W. (2014). PERGESERAN EPISTEMOLOGI PENDIDIKAN ISLAM. Al-Adabiya: Jurnal Kebudayaan Dan Keagamaan, 9(1), 14.

http://ejournal.kopertais4.or.id/mataraman/index.php/alabadiyah/article/view/666

Langgulung, H. (1980). Beberapa Pemikiran Tentang Pendidikan Islam. Ma'arif. https://books.google.co.id/books?id=6bO1AQAACAAJ

Langgulung, H. (1984). Dayacipta dalam kurikulum pendidikan guru. Penerbit Universiti Kebangsaan Malaysia. https://books.google.co.id/books?id=7_eoGwAACAAJ

Langgulung, H. (1985). Pendidikan dan peradaban Islam: suatu analisa sosio-psikologi. Pustaka AlHusna, Jakarta. https://books.google.co.id/books?id=ofCgAQAACAAJ

Langgulung, H. (1986). Manusia Dan Pendidikan: Suatu Analisa Psikologi, Filsafat Dan Pendidikan. Pustaka al-Husna. https://books.google.co.id/books?id=feeuAQAACAAJ

Langgulung, H. (1988). Pendidikan Islam menghadapi abad ke-21. Pustaka Al Husna. https://books.google.co.id/books?id=SS0aAAAAIAAJ

Langgulung, Hasan. (2003). Pendidikan Islam dalam abad ke-21. Pustaka Al Husna Baru. https://books.google.co.id/books?id=t1V3AAAACAAJ

Martin, O. (2017). Metode Penelitian Dalam Ilmu Sosial. CreateSpace Independent Publishing Platform. https://books.google.co.id/books?id=0lygswEACAAJ

Munawwir, A. W., Ma'shum, A., \& Munawwir, Z. A. (2002). المنور: kamus Arab-Indonesia. Pustaka Progressif. https://books.google.co.id/books?id=PbPFHAAACAAJ

Mustajib, H. (2016). Filsafat Pendidikan Hasan Langgulung. El-Tarbawi: Jurnal Penddidikan Islam, 9(2). 
Pantiwati, Y., Restian, A., \& Sumarsono, P. (2016). Belajar dan Pembelajaran. UMMPress. https://books.google.co.id/books?id=F5xjDwAAQBAJ

Riza, M. (2017). Epistimologi Pendidikan Islam Perspektif Hasan Langgulung. Jurnal As-Salam, $1(2), 38-46$.

Velasquez, M. G. (1991). Philosophy, a Text with Readings. Wadsworth Publishing Company. https://books.google.co.id/books?id=4eTZAAAAMAAJ

Wikipedia, B. $\quad$ I. (2019). Biografi Hasan Langgulung. https://id.wikipedia.org/wiki/Hasan_Langgulung

Wilatikta, A. (2020). Manajemen Kurikulum Pendidikan Agama Islam Jenjang Pendidikan Dasar: Kontekstualisasi Strategi Pembelajaran Semasa Pandemi. Ta'lim, 2(2), 1-12.

Zed, M. (2014). Metode Penelitian Kepustakaan. Yayasan Pustaka Obor Indonesia. https://books.google.co.id/books?id=zG9sDAAAQBAJ 
MEMAKNAI ULANG KONSEP PENDIDIKAN ISLAM (TELAAH KRITIS EPISTEMOLOGI ...

Ima Frafika Sari, Ucup Supriatna, Afni Ma'rufah 